\title{
Prevalence, Awareness, Treatment, and Control of Hypertension in the Inner City ${ }^{1}$
}

\author{
K. Michael Cummings, ${ }^{* 2}$ John P. Kirscht, $\dagger$ \\ LAURENCE R. Binder, $\ddagger$ AND ALegro Godley $\$$ \\ *Department of Cancer Control and Epidemiology, Roswell Park Memorial Institute, \\ Buffalo, New York 14263, †Department of Health Behavior and Health Education, \\ School of Public Health, University of Michigan, Ann Arbor, Michigan 48109, and \\ $\ddagger$ Detroit Hypertension Control Program, Detroit Health Department, \\ Detroit, Michigan 48202
}

This article reports on the prevalence, awareness, treatment, and control of hypertension in a predominantly black population residing in the inner city of Detroit, Michigan. The data reported come from a cross-sectional survey of approximately 800 adults conducted in the fall of 1978. The prevalence of hypertension in the population studied, $38 \%$, was similar for men and women below age 55; above age 55, women were more likely to have high blood pressure than men. Hypertension was positively related to the respondent's age and weight, but was not associated with having a family history of hypertension, or with the amount of cigarettes smoked daily. Compared with estimates of awareness, treatment, and control status of hypertensives derived from community surveys conducted in the $1960 \mathrm{~s}$, our findings indicate substantial improvement in hypertension management among a predominately black, urban population during the past decade. Of the hypertensives identified in our sample, $80 \%$ were aware of their hypertension before participation in the survey, $86 \%$ of those previously detected were being treated for their hypertension, and $26 \%$ of those being treated were adequately controlled $(\mathrm{BP}<140 / 90 \mathrm{~mm} \mathrm{Hg}$ ). Awareness, treatment, and control rates appear to be age-related, with younger respondents less likely to be aware of their hypertension, on antihypertensive therapy, and successfully controlled. Below age 54, women were much more likely to be aware of their hypertension condition than men. Because of the lower detection rates among younger age groups it is recommended that future blood pressure screening efforts in the inner city be directed at younger adults (between the ages of 18 to 44 ), especially men.

\section{INTRODUCTION}

Morbidity and mortality rates from cardiovascular disease (CVD) remain extremely high in the United States and constitute one of the principal challenges to medical science and public health. Numerous epidemiologic and actuarial studies have demonstrated that high blood pressure is a major independent risk factor associated with the development of heart disease and stroke $(4,10-13)$. The findings from these studies are further supported by experimental investigations which have demonstrated that medically controlling high blood pressure reduces CVD morbidity and mortality $(8,27,28)$.

${ }^{1}$ This research was supported by Grant HL-22380-1 from the National Heart, Lung and Blood Institute.

${ }^{2}$ To whom reprint requests should be addressed: Dr. K. M. Cummings, Department of Cancer Control and Epidemiology, Roswell Park Memorial Institute, 666 Elm Street, Buffalo, New York 14263. 
Despite the availability and efficacy of treatment for hypertension many people with elevated blood pressure are not diagnosed, and among those who are, many are receiving inadequate or no treatment for their condition. A commonly mentioned rule of thumb derived mainly from data gathered in community surveys in the 1960s suggested that approximately one-half of all hypertensives screened were unaware of their hypertension, half of those detected were not under treatment, and only half of the hypertensives being treated were adequately controlled $(19,21,30)$. In a survey of adults 25 to 60 years of age, conducted in Detroit, Michigan in 1968, it was found that $51 \%$ of those with high blood pressure were unaware of their hypertension before participating in the survey, $33 \%$ of those with high blood pressure were not receiving treatment for their hypertension, and only $28 \%$ of those being treated had their blood pressure adequately controlled, with control status defined as systolic pressure less than $140 \mathrm{~mm} \mathrm{Hg}$ and diastolic pressure less than $90 \mathrm{~mm} \mathrm{Hg} \mathrm{(5).}$

Community surveys conducted since 1970 have revealed a substantial improvement in hypertension management $(7,25,29)$. For instance, the Hypertension Detection and Follow-up Program, a national study in which over 150,000 people were screened for high blood pressure between 1973 and 1974, found that $75 \%$ of the hypertensives screened were aware of their hypertension, $72 \%$ of those aware received treatment, and of those treated, $70 \%$ had diastolic blood pressure less than $95 \mathrm{~mm} \mathrm{Hg}$ (29).

While the results from the Hypertension Detection and Follow-up Program and other recently conducted community surveys suggest an overall improvement in hypertension detection and management during the past decade, it is difficult to assess whether improvements in blood pressure control are shared equally among all subgroups in the population. In particular, there is little information available on the detection, treatment, and control of black hypertensives from an urban population. In the United States, the prevalence of hypertension is about twice as high among blacks as compared with whites $(19,20)$.

This article reports on the prevalence, awareness, treatment, and control of hypertension in a predominantly black population in the inner city of Detroit, Michigan in 1978. In addition, data are presented on the associations between hypertension and age, sex, relative weight, family history of hypertension, and cigarette smoking.

\section{MATERIALS AND METHODS}

The data analyzed in this article were collected as part of the Detroit Hypertension Study, a 5-year demonstration program designed to evaluate the effectiveness of an intensive blood pressure screening, referral, and follow-up effort in increasing the number of controlled hypertensives in a predominantly black population in an inner city area of Detroit, Michigan. The research design for that study involves a comparison of two matched areas, one exposed to the blood pressure screening referral and follow-up program and the other not provided with any special blood pressure control services. Each area consisted of 13 census tracts, containing about 50,000 adults. The study is now in its fourth ycar. This article 
reports on the data collected in the baseline survey of the two areas conducted in the fall of 1978 .

\section{Sample Survey}

A two-stage probability sample was drawn to represent the noninstitutionalized population of adults (age 18 and older) residing in the two study areas. In the first stage of the sample, 1,454 households (702 from study area 1, and 752 from study area 2) were selected at random from the city directory. The directory listing was supplemented by information on new construction and demolition of households as well as updated listings from earlier surveys. Addresses which contained five or more housing units were separately listed and sampled. If an address contained four or fewer housing units, all four units were included in the sample.

In the second stage of the sample, one adult in each designated household was randomly selected to be interviewed. Of the 1,454 household addresses sampled, 275 were dropped because the households were vacant, the addresses selected were not private households, or the addresses could not be located, leaving 1,179 eligible households. Blood pressure determinations were made on 773 respondents, representing an overall response rate of $66 \%$ of the eligible sample.

The demographic characteristics of respondents in the sample were compared with the characteristics of the population in the survey area to evaluate how well the sample represented the population. Table 1 presents the distributions of selected demographic characteristics for respondents in the sample and the population in the survey area. The demographic characteristics of the population in the survey area are estimated from the results of a $1.5 \%$ cross-sectional probability sample of housing units which was conducted in the city of Detroit in 1976. In general, the demographic characteristics of respondents in the sample closely resemble the characteristics of the population residing in the survey area. However, women and persons with an annual income of less than $\$ 10,000$ appear to be slightly overrepresented in the sample.

\section{Measures}

Hypertension. Blood pressure measurements were obtained according to a standard protocol by trained interviewers who were periodically tested for accuracy of measurement. Three consecutive blood pressure measurements were made on the left arm of each person interviewed with a standard mercury sphygmomanometer when the person had been seated for at least $5 \mathrm{~min}$. A reading was classified as high if the systolic pressure was greater than $160 \mathrm{~mm} \mathrm{Hg}$, or if the diastolic pressure was $95 \mathrm{~mm} \mathrm{Hg}$, or higher. The 5 th phase diastolic pressure was used to define the diastolic reading. A person was considered hypertensive if two or more of the readings were classified as high or when two out of three blood pressure readings were normal, if the person was on treatment for hypertension.

In addition to blood pressure determinations, respondents were asked questions about their health status, use of antihypertensive medications, family history of hypertension, tobacco use, weight and height, and demographic characteristics.

Awareness of hypertension. Respondents with hypertension who reported in 
TABLE 1

Distribution of Selected Demographic Characteristics for Respondents in the Sample and the Population in the Survey Area

\begin{tabular}{lccr}
\hline $\begin{array}{c}\text { Demographic } \\
\text { characteristics }\end{array}$ & $\begin{array}{c}\text { Percentage in } \\
\text { 1978 sample }\end{array}$ & $\begin{array}{c}\text { Percentage in survey } \\
\text { area population based } \\
\text { on 1976 estimates }\end{array}$ & Difference \\
\hline Age & & & \\
$18-21$ years & 6.7 & 10.8 & -4.1 \\
$22-34$ years & 26.7 & 23.9 & 2.8 \\
35-49 years & 18.6 & 22.4 & -3.8 \\
50-64 years & 28.9 & 26.3 & 2.6 \\
65 years or older & 19.1 & 16.6 & 2.5 \\
Percent black & 97.5 & 97.0 & 0.5 \\
Percent female & 64.3 & 55.5 & 8.8 \\
Years of school completed & & & \\
Less than 8 th grade & 24.5 & 24.0 & -2.5 \\
8th grade to 11 th grade & 25.4 & 28.0 & 3.4 \\
12th grade & 35.4 & 32.0 & 0.9 \\
Some college & 11.6 & 10.5 & -2.4 \\
College graduate & 3.1 & 5.5 & \\
Annual household income & & & 3.0 \\
Under \$5,000 & 32.8 & 29.7 & 7.1 \\
\$5,000-\$9,999 & 36.4 & 29.3 & -4.3 \\
\$10,000-\$14,999 & 14.1 & 18.4 & -1.7 \\
\$15,000- \$19,999 & 8.3 & 10.0 & -4.1 \\
\$20,000 or more & 8.4 & 12.5 & \\
\hline
\end{tabular}

${ }^{a}$ Population estimates for the survey area are based on estimates from a $1.5 \%$ cross-sectional probability sample of housing units in the city of Detroit in 1976.

the interview that they had previously been told by a doctor that they have high blood pressure were classified as "aware" of their hypertension. Persons with hypertension who reported that they had not ever been told by a doctor that they have high blood pressure were classified as "unaware" of their hypertension.

Treatment status. Respondents with hypertension who indicated in the interview that they were taking antihypertensive medication or were presently under doctor's care for high blood pressure were classified as on treatment for hypertension.

Hypertension control. Studies which have reported on the blood pressure control status of hypertensives have used different criteria to define hypertension control. The majority of studies have defined hypertension control as a systolic pressure less than $160 \mathrm{~mm} \mathrm{Hg}$ and a diastolic pressure less than $95(7,19,21,25$, $29,30)$. However, some studies have used a more restrictive definition of hypertension control as systolic pressure less than $140 \mathrm{~mm} \mathrm{Hg}$ and diastolic pressure less than $90 \mathrm{~mm} \mathrm{Hg}$. (5).

In this paper, hypertension control was defined in two ways. First, for persons on treatment for high blood pressure, hypertension was considered adequately controlled if two out of three blood pressure readings were systolic less 
than $160 \mathrm{~mm} \mathrm{Hg}$, and diastolic less than $95 \mathrm{~mm} \mathrm{Hg}$. The second definition of hypertension control defined persons on treatment for high blood pressure as adequately controlled if two out of three blood pressure readings were systolic less than $140 \mathrm{~mm} \mathrm{Hg}$, and diastolic less than $90 \mathrm{~mm} \mathrm{Hg}$.

Relative weight. Relative weight was computed for each respondent by forming the ratio of his/her reported body weight (without heavy clothes on) to the desirable weight for his/her particular sex-height group according to standards set by the Metropolitan Life Insurance Company (17). The desirable weight for a given sex-height group, was defined as the midpoint of the range for medium frame individuals. The ratio of reported body weight to desirable weight was expressed as a whole number in percent. In these analyses the relative weight measure was divided into six categories as follows: (a) less than desirable, (b) desirable weight to $10 \%$ above desirable weight, (c) 11-20\% above desirable weight, (d) 21-30\% above desirable weight, (e) 31-40\% above desirable weight, and (f) over $40 \%$ above desirable weight.

Family history of hypertension. A respondent was classified as having a family history of hypertension if any of their grandparents, parents, brothers, or sisters had ever had high blood pressure.

Cigarette smoking. Respondents were questioned about their use of tobacco in the interview. A person's cigarette smoking behavior was classified into three categories: (a) nonsmoker, which included ex-smokers and nonsmokers, (b) current cigarette smokers who smoke less than one half pack of cigarettes per day, and (c) current cigarette smokers who smoke more than one half pack of cigarettes per day.

\section{Analysis Methods}

For the purposes of controlling the possible confounding effects of age when evaluating the associations between hypertension and relative weight, family history of hypertension, and cigarette smoking, adjusted odds ratios are computed following the Mantel-Haenszel procedure (15). The significance test used for these odds ratios is the $\chi^{2}$. Confidence intervals for category specific odds ratios are estimated using the procedure suggested by Miettinen (18). The prevalence rates given in Tables 3,4 , and 5 are age adjusted to the 1970 United States population. In the tables presented, the column totals for respondents do not always equal 773 due to isolated instances of missing interview data.

\section{RESULTS}

\section{Prevalence}

The prevalence of hypertension in the study sample is $38 \%$. As shown in Fig. 1, the prevalence rates for hypertension increase with age for both men and women. The rates of hypertension are similar for men and women below age 54; above age 55 , women are more likely to have hypertension.

\section{Awareness, Treatment, and Control of Hypertension}

Table 2 shows the awareness, treatment, and control status of hypertensives by age and sex. Of the 291 hypertensives in the sample, $80 \%$ were aware of their 


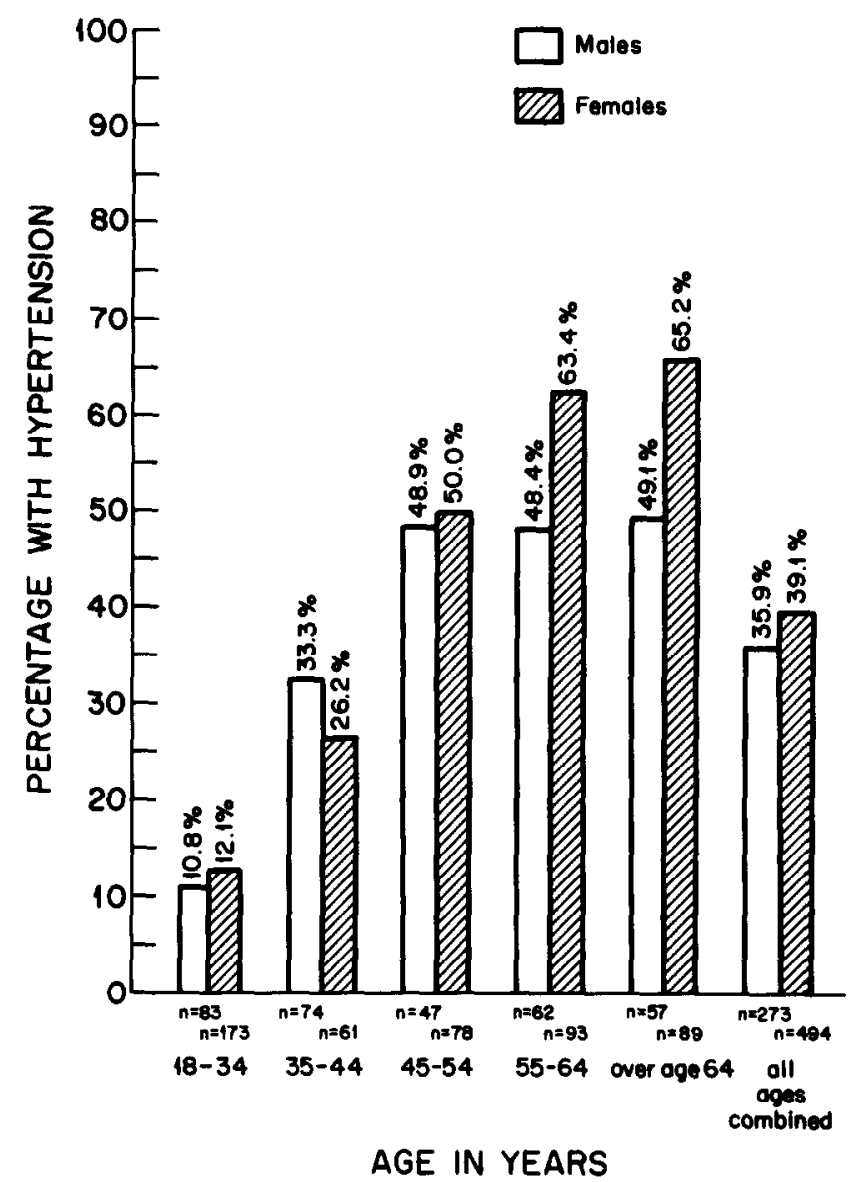

Fig. 1. Prevalence of hypertension by agc and scx.

hypertension before participation in the survey. Below age 54, women are much more likely to be aware of their hypertension than men. Prior detection rates increase with age for both sexes. Of the 234 hypertensives aware of their hypertension prior to participation in the survey, $86 \%$ were being treated for their condition. Treatment rates increase with age. Of the 201 hypertensives on treatment for hypertension, $58 \%$ had their blood pressure adequately controlled, with control status defined as two out of three blood pressure readings less than 160 $\mathrm{mm} \mathrm{Hg}$ systolic, and $95 \mathrm{~mm} \mathrm{Hg}$ diastolic. Twenty-six percent of hypertensives on treatment had their blood pressure adequately controlled, with control status defined as two out of three blood pressure readings less than $140 \mathrm{~mm} \mathrm{Hg}$ systolic, and $90 \mathrm{~mm} \mathrm{Hg}$ diastolic.

\section{Hypertension and Relative Weight}

The levels of risk of having hypertension associated with deviations from desirable weight are shown in Table 3 . The age adjusted odds ratios indicate that there 


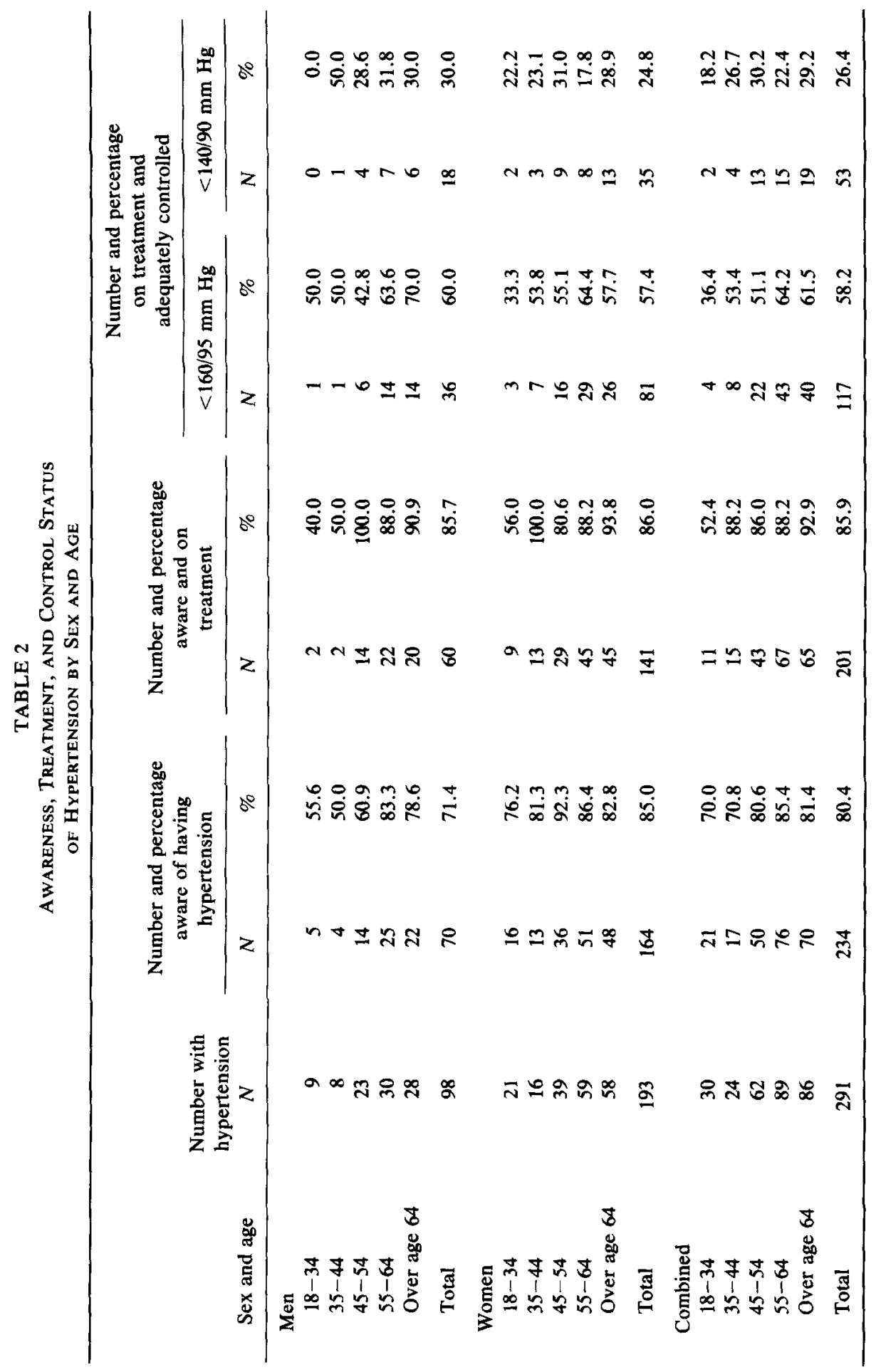


TABLE 3

Association between Hypertension and Deviations from Desirable Weight

\begin{tabular}{lrccc}
\hline \multicolumn{1}{c}{$\begin{array}{c}\text { Deviations from } \\
\text { desirable weight }\end{array}$} & $N$ & $\begin{array}{c}\text { Percentage with } \\
\text { hypertension }^{a}\end{array}$ & $\begin{array}{c}\text { Adjusted } \\
\text { odds ratio }\end{array}$ & $\begin{array}{c}\text { 95\% } \\
\text { confidence interval }\end{array}$ \\
\hline Less than desirable weight & 189 & 24.1 & 0.86 & $0.55-1.33$ \\
Desirable weight to 10\% above & 163 & 27.5 & 1.00 & \\
$11 \%-20 \%$ above desirable weight & 139 & 36.1 & 1.65 & $0.92-2.94$ \\
$21 \%-30 \%$ above desirable weight & 101 & 39.1 & $1.98^{*}$ & $1.08-3.61$ \\
$31 \%-40 \%$ above desirable weight & 56 & 46.1 & $2.11^{*}$ & $1.04-4.27$ \\
Over 40\% above desirable weight & 105 & 47.2 & $2.59^{*}$ & $1.46-4.59$ \\
Total & 753 & 34.2 & & \\
\hline
\end{tabular}

${ }^{a}$ Age adjusted to the 1970 United States population.

$* P<0.05$.

is an increase in risk of hypertension with an increase in deviations above desirable weight. The age adjusted odds ratios associated with the three highest categories of deviations above desirable weight relative to within $10 \%$ above desirable are significantly elevated $(P<0.05)$.

\section{Hypertension and Family History}

Fifty-six percent of respondents in our sample had a family history of hypertension. The age adjusted odds ratio in Table 4 indicates a slight increase in risk of hypertension associated with having a family history of hypertension. However, the increased risk of hypertension associated with having a family history of hypertension relative to no family history is not statistically significant at the 5\% level.

\section{Hypertension and Cigarette Smoking}

Table 5 shows the risk of hypertension for smokers of less than a half pack of cigarettes a day and smokers of more than half a pack of cigarettes per day relative to nonsmokers. The age adjusted odds ratios indicate a slight increase in the risk of hypertension associated with cigarette smoking. However, smokers of less than

TABLE 4

Association between Hypertension and Family History of Hypertension

\begin{tabular}{ccccc}
\hline Family history & $N$ & $\begin{array}{c}\text { Percentage with } \\
\text { hypertension }^{a}\end{array}$ & $\begin{array}{c}\text { Adjusted } \\
\text { odds ratio }\end{array}$ & $\begin{array}{c}95 \% \\
\text { confidence interval }\end{array}$ \\
\hline $\begin{array}{c}\text { Family history } \\
\text { of hypertension }\end{array}$ & 432 & 37.5 & 1.36 & $0.95-1.95$ \\
$\begin{array}{c}\text { No family history } \\
\text { of hypertension }\end{array}$ & 333 & 31.6 & 1.00 & \\
Total & 765 & 34.6 & & \\
\hline
\end{tabular}

${ }^{a}$ Age adjusted to the 1970 United States population. 
TABLE 5

Association between Hypertension and Cigarette SMoking

\begin{tabular}{lcccc}
\hline Cigarette smoking behavior & $N$ & $\begin{array}{c}\text { Percentage with } \\
\text { hypertension }^{a}\end{array}$ & $\begin{array}{c}\text { Adjusted } \\
\text { odds ratio }\end{array}$ & $\begin{array}{c}95 \% \\
\text { confidence interval }\end{array}$ \\
\hline Nonsmoker or ex-smoker & 373 & 31.1 & 1.00 & \\
$<10$ cigarettes per day & 193 & 39.7 & 1.45 & $0.92-2.27$ \\
$\geqslant 10$ cigarettes per day & 197 & 32.7 & 1.04 & $0.38-2.81$ \\
Total & 763 & 34.4 & & \\
\hline
\end{tabular}

${ }^{a}$ Age adjusted to the 1970 United States population.

a half pack of cigarettes per day have a higher risk of hypertension than smokers of more than half a pack of cigarettes per day relative to nonsmokers.

\section{DISCUSSION}

The $38 \%$ prevalence rate for hypertension found in this study is similar to prevalence rates obtained in other epidemiological investigations done in predominately black populations $(19,20,29)$. The higher prevalence of hypertension observed in women compared with men over age 55 is consistent with the findings of the National Health Examination Survey $(19,20)$. The positive associations found between hypertension and age and percentage overweight are also in agreement with findings from numerous epidemiological studies $(2,3,5,9,14,19$, 20, 29).

In contrast to the conclusions of several studies $(2,5,6,22,23)$, which suggest a genetic predisposition for hypertension, we found only a small increased risk of hypertension associated with having a family history of hypertension. However, the obtained rates of family history of hypertension in this study were high and may reflect erroneous identification of the condition in other family members. Also, since our estimates of risk are based on prevalence data, they may not be comparable to risk estimates from prospective studies utilizing incidence data.

Our finding of no dose-response association between cigarette smoking and hypertension is in agreement with most available epidemiological data which indicates that cigarette smoking is not a major risk factor for hypertension $(1,26)$. In fact, present evidence suggests that cigarette smoking may be associated with mild chronic hypotensive effects (16).

Compared with estimates of awareness, treatment, and control status of hypertensives derived from community surveys conducted in the 1960s, our findings indicate substantial improvement in hypertension management among a predominately black, urban population during the past decade. Figure 2 presents estimates of the awareness, treatment, and control status of hypertensives from a survey of the Detroit population conducted in 1968 (5), and similarly derived estimates from our 1978 survey. In 1968, it was estimated that $51 \%$ of the hypertensives in Detroit were unaware of the fact they had hypertension. In contrast, only $20 \%$ of the hypertensives found in 1978 were unaware of their hypertension. In 1968, only $35 \%$ of Detroit area residents with hypertension were receiving treatment for their 


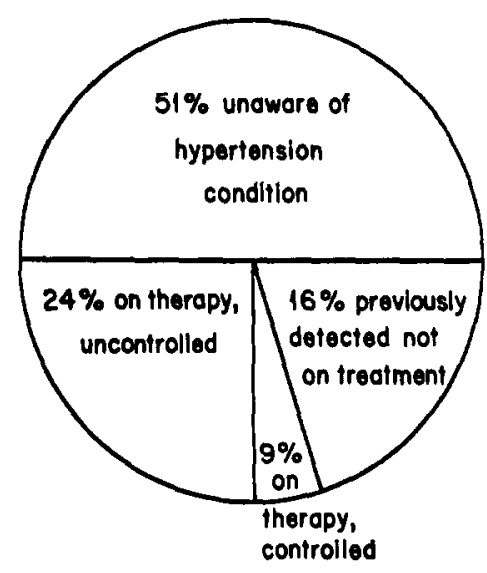

1968 SURVEY

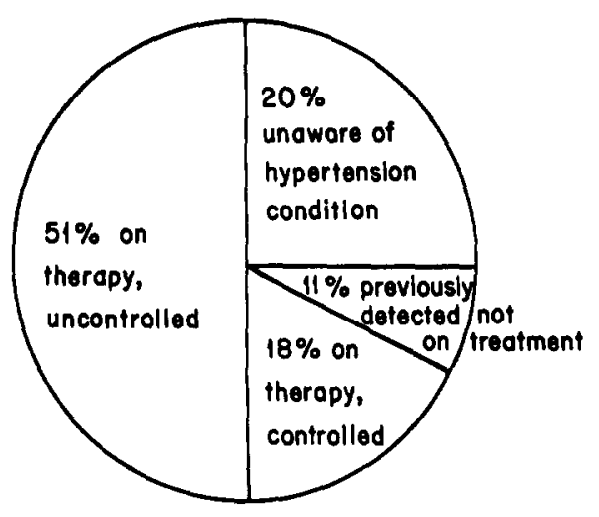

1978 SURVEY

FIG. 2. Percentage of all hypertensives who are aware of their hypertension, who are on antihypertensive therapy, and whose blood pressure is under control (BP $<140 / 90 \mathrm{~mm} \mathrm{Hg}$ ) by date of survey.

condition. Data from our 1978 survey showed that over $70 \%$ of hypertensives were receiving treatment for their condition.

Despite a sizeable increase in the proportion of people under treatment for hypertension since 1968, the population found to be under adequate treatment (blood pressure readings below $140 / 90 \mathrm{~mm} \mathrm{Hg}$ ) has not increased a great deal. In $1968,9 \%$ of the hypertensives identified had two out of three blood pressure readings below $140 \mathrm{~mm} \mathrm{Hg}$ systolic and $90 \mathrm{~mm} \mathrm{Hg}$ diastolic. In 1978, 18\% of hypertensives identified had two out of three blood pressure readings below 140 $\mathrm{mm} \mathrm{Hg}$ systolic and $90 \mathrm{~mm} \mathrm{Hg}$ diastolic. While the changes evident in Figure 2 are clearly improvements, there still remains a large number of hypertensives who are either not on treatment or inadequately treated. It is apparent that screening alone is not a sufficient method for controlling hypertension. Successful control of hypertension will not only require widespread screening for detection of people with the disease but will also require procedures to insure long-term maintenance of appropriate antihypertensives therapies. With regard to detection of hypertension, our findings indicate that blood pressure screening programs in the inner city should be directed towards adults between the ages of 18 and 44 , especially men. About half the men in our sample between the ages of 18 and 44 who had hypertension were not aware of their hypertension before participation in the survey.

\section{REFERENCES}

1. Berglund, G., and Wilhelmsen, L. Factors related to blood pressure in a general population sample of Swedish men. Acta. Med. Scand. 198, 291-298 (1975).

2. Clark, V. A., Chapman, J. M., and Coulson, A. H. Effects of various factors on systolic and diastolic blood pressure in the Los Angeles heart study. J. Chron. Dis. 20, 571-581 (1967).

3. Chiang, B. N., Perlman, L. V., and Epstein, F. H. Overweight and hypertension: A review. Circulation 39, 403-421 (1969). 
4. Epstein, F. H., Ostrander, Jr., L. D., Johnson, B. C., Payne, M. W., Hayner, N. S., et al. Epidemiological studies of cardiovascular disease in a total community-Tecumseh, Michigan. Ann. Intern. Med. 62, 1170-1187 (1965).

5. Foote, A., Erfurt, J. C., and Caldwell, J. R. A screening, referral and follow-up program for high blood pressure at Henry Ford Hospital: Part I. Results of screening. Henry Ford Hosp. Med.J. 24, 69-79 (1976).

6. Hayes, C., Tyroler, H., and Cassel, J. Family aggregation of blood pressure in Evans County, Georgia. Arch. Int. Med. 128, 965-975 (1971).

7. Hypertension Detection and Follow-up Program Cooperative Group. Blood pressure studies in 14 communities: A two stage screening for hypertension. JAMA 237, 2385-2391 (1977).

8. Hypertension Detection and Follow-up Program Cooperative Group. Five-year findings of the Hypertension Detection and Follow-up Program. I. Reduction in mortality of persons with high blood pressure, including mild hypertension. JAMA 242, 2562-2571, (1979).

9. Kannel, W. B., Brand, N., Skinner, Jr., J. J., Dawber, T. R., and McNamara, P. M. The relation of adiposity to blood pressure and development of hypertension: The Framingham study. Ann. Intern. Med. 67, 48-59 (1967).

10. Kannel, W. B., Castelli, W. P., McNamara, P. M., McKee, P. A., and Feinleib, M. Role of blood pressure in the development of congestive heart failure. New Engl. J. Med. 287, 781-787 (1972).

11. Kannel, W. B., Wolf, P. A., Verter, J., and McNamara, P. M. Epidemiological assessment of the role of blood pressure in stroke. JAMA 214, 301-310 (1970).

12. Keys, A., Aravanis, C., Blackburn, H., Van Buchem, F. S., Buzina, R., et al. Probability of middle-aged men developing coronary heart disease in five years. Circulation $45,815-828$ (1972).

13. Lcw, E. A. High blood pressure, other risk factors and longevity: The insurance vicwpoint. Amer. J. Med. 55, 281-294 (1973).

14. Mann, G. U. The influence of obesity on health. New Engl. J. Med. 291, 178-185 (1974).

15. Mantel, N., and Haenszel, W. Statistical aspects of the analysis of data from retrospective studies of disease. J. Natl. Cancer Inst. 22, 719-748 (1959).

16. McMillan, G. C. Cardiovascular diseases, in "U.S. Public Health Service. Smoking and Health: A Report of the Surgeon General." DHEW Publication No. (PHS) 79-50066, Chapter 4. U.S. Department of Health, Education, and Welfare, Public Health Service, 1979.

17. Metropolitan Life Insurance Company. "Four Steps to Weight Control,"' p. 12. Metropolitan Life Insurance Company, 1969.

18. Miettinen, O. Estimability and estimation in case-referent studies. Amer. J. Epid. 103, 226-234 (1976).

19. National Center for Health Statistics. Blood pressure of adults by age and sex, United States 1960-1962. Series 11, No. 4, June 1964.

20. National Center for Health Statistics. Blood pressure of persons 18-74 years, United States 1971-1972. Series 11, No. 150, April 1975.

21. Schoenberger, J. A., Stamler, J., Shekelle, R. B., and Shekelle, S. Current status of hypertension control in an industrial population. JAMA 222, 559-562 (1972).

22. Schull, W. J., Harburg, E., Erfurt, J. C., Schork, M. A., and Rice, R. A family set method for estimating heredity and stress: II. Preliminary results of the genetic methodology in a pilot study of negro blood pressure, Detroit, 1966-67. J. Chron. Dis. 23, 83-92 (1970).

23. Schull, W. J., Harburg, E., Schork, A., Weener, J., and Chape, C. Heredity, stress and blood pressure, a family set method. III. Family aggregation of hypertension. J. Chron. Dis. 30, 659-669 (1977).

24. Stamler, J., Rhomberg, P., Schoenberger, J. A., Shekelle, R. B., Dyer, A., et al. Multivariate analysis of the relationship of seven variables to blood pressure: Findings of the Chicago Heart Association Detection Project in Industry, 1967-1972. J. Chron. Dis. 28, 527-548 (1975).

25. Stamler, J., Stamler, R., Riedlinger, W. F., Alger, G., and Roberts, R. H. Hypertension screening of 1 million Americans: Community Hypertension Evaluation Clinic (CHEC) Program, 1973 through 1975. JAMA 235, 2299-2306 (1976). 
26. U.S. Public Health Service. The Health Consequences of Smoking. A reference edition: 1976. DHEW Publication No. (CDC) 78-8357. U.S. Department of Health, Education, and Welfare, Center for Disease Control, 1976.

27. Veterans Administration Cooperative Study Group on Antihypertensive Agents. Effects of treatment on morbidity in hypertension-Results in patients with diastolic blood pressure averaging 115 through $129 \mathrm{~mm}$ Hg. JAMA 202, 1028-1034 (1967).

28. Veterans Administration Cooperative Study Group on Antihypertensive Agents. Effects of treatment on morbidity in hypertension. II. Results in patients with diastolic blood pressure averaging 90 through $114 \mathrm{~mm} \mathrm{Hg.} \mathrm{JAMA} \mathrm{213,} \mathrm{1143-1152} \mathrm{(1970).}$

29. Wassertheil-Smoller, S., Apostolides, A., Miller, M., Oberman, A., and Thom, T. Recent status of detection, treatment and control of hypertension in the community. J. Community Health 5 , 82-93 (1979).

30. Wilber, J. A., and Barrow, J. G. Reducing elevated blood pressure: Experience found in a community. Minn. Med. 52, $1033-1306$ (1969). 